\title{
A Modified, Rapid and Safe Technique of Kidney Only Procurement from Donors after Circulatory and Brain Death (DCD, DBD)
}

\author{
André G. Baranski, Hwai-Ding Lam \\ Department of Transplantation Surgery, Leiden University Medical Center, Leiden, Netherlands \\ Email: a.baranski@lumc.nl
}

How to cite this paper: Baranski, A.G. and Lam, H.-D. (2016) A Modified, Rapid and Safe Technique of Kidney Only Procurement from Donors after Circulatory and Brain Death (DCD, DBD). Open Journal of Organ Transplant Surgery, 6, 23-28.

http://dx.doi.org/10.4236/ojots.2016.64004

Received: July 30, 2016

Accepted: October 30, 2016

Published: November 4, 2016

Copyright $\odot 2016$ by authors and Scientific Research Publishing Inc. This work is licensed under the Creative Commons Attribution International License (CC BY 4.0).

http://creativecommons.org/licenses/by/4.0/

\begin{abstract}
There is currently a lack of standard kidney-only procurement technique. Known techniques such as kidney-only procurement using the standard multi-organ procurement technique could potentially cause more iatrogenic injuries due to less adequate exposure. An alternative using the live open kidney donation technique could also be less than ideal due to prior unknown anatomical variation and potential the inability to adequately topically cool the kidneys. We describe here a novel easy kidney-only technique leading to an improved exposure, better cold perfusion and topical cooling. Herein we show how total bowel evisceration can be achieved by stapling the hepatic hilum, superior mesenteric artery and coeliac trunk. There is a need of a kidney only procurement in order to increase the quality of deceased kidney donation in our opinion. Results have to be compared in the future to determine the potential benefits.
\end{abstract}

\section{Keywords}

Organ Procurement, Kidney, Transplantation, Kidney Donation, Surgical Technique

\section{Introduction}

In the modern era of organ transplantation, with an increasing organ shortage, successful procurement of any suitable organs becomes of paramount importance. In the Netherlands, patients can decide which organs they are willing to donate in case they become donors. As a consequence, kidney only donations can be a result of these wishes. In other instances only kidneys are procured because other organs are not suitable for transplantation. 
Herein we describe a technique of kidney only procurement which is rapid and easy to learn. It provides a stable, safe and clear operative field. This is crucial in order to avoid any injuries during identification and dissection of anatomical structures. The advantages of this technique could be a more rapid procurement with less preservation fluid necessary for adequate flushing.

\section{Technique}

In donation after circulatory death (DCD), it is of great importance to get the aortic cannula in as soon as possible. This is to limit the warm ischemia time. Briefly, this is done by performing a midline laparotomy from the xyphoid to pubis. The skin is grabbed with two Backhaus clamps and lifted away from the bowels when making the incision. Once the abdomen is opened, the incision can then be extended cranially and caudally with Mayo scissors cutting through the fascia. This is faster and safer than using a blade. The assistant, standing on the donor left hand side then lifts up the small bowels towards the head and laterally to the left of the abdomen, thereby exposing the aorto-iliac bifurcation. The surgeon will then incise the parietal peritoneum overlying the aorto-iliac bifurcation. One landmark that can be used is the sacral promontory. Once the parietal peritoneum is incised, the surgeon uses his two index fingers to blunt dissect the aorta-iliac bifurcation. He then places a large vascular clamp on the distal aorta just above the bifurcation, and with his left hand pinches the aorta proximal $3 \mathrm{~cm}$ away from the clamp. This is followed by an aortotomy. The cannula is then inserted after it has been flushed with preservation fluid and the perfusion can then start. The cannula is then secured to the aorta with a tie around the aorta or with an Allis clamp placed on top of the cannula. If a tie is chosen, the surgeon uses his right hand to loop around the aorta while holding the cannula in place with his left hand. The assistant can secure the cannula with a tie. Small lumbar backflow can be controlled by placing a Kocher or a vascular clamp underneath the aortic cannula. In case the aorta is too sclerotic, cannulation can take place in the right iliac artery. The right ureter, which lies just proximal across the internal-external iliac arterial bifurcation, must be avoided during dissection. In donation after brain death (DBD), where there is no time pressure, the aorto-iliac bifurcation can be dissected at ease in the warm with electro cautery. This is done after mobilising the whole mesenterial contents to the left by performing a combined Cattel-Braaschl and Kocher manoeuvre. The inferior mesenteric artery is also divided. Heparin intravenously is given shortly before cannulation.

Next venting is performed by ligating the proximal inferior vena cava (IVC) and inserting a thoracic drain or a suction drain after the venotomy. The drain is fixated with a tie to the distal IVC. It is important to insert the drains far enough. This prevents leakage into the abdominal cavity. Similarly as in DVD, venting is done in the cold with $\mathrm{DBD}$, but the IVC can already looped before cold perfusion. In DCD after venting, the omnitract is then placed and the bowels are put back in its anatomical position. The next step is to clamp the aorta proximal of the coeliac trunk. This is done to increase the amount of perfusion going to the abdominal organs. The left triangular ligament is 
mobilized before lifting the left liver lobe to the right in order to achieve maximal exposure of diaphragmatic crura. The pars flaccida of the gastrohepatic ligament is opened and diaphragmatic crura are divided, thereby exposing the supra-celiac aorta. This is looped and subsequently clamped after perfusion in DBD. An alternative is to cut down the left diaphragm and clamp the thoracic aorta above the diaphragm. In difficult cases, the access to the supracoeliac aorta can also be obtained by quick division of hepatoduodenal ligament with a vascular stapler. The liver is then subsequent cranio-lateral retracted and the pancreatic head retracted caudo-medially, using retractors or manually by the operative assistant (Figure 1). This opens a wider route towards the supracoeliac aorta. Again here the diaphragmatic crura that typically lie on top of aorta are first divided before gaining access to the supra-coeliac aorta.

After clamping the supracoeliac aorta a combined Cattel-Braaschl with Kocherisation is performed in DCD. The whole viscera is then mobilised from right to left. From this point both DBD and DCD procurement are done in the same manner during the cold dissection. The proximal jejunum is divided at the angle of Treitz. This is done to gain access to the Superior Mesenteric Artery (SMA) and the Coeliac Trunk (CT). The SMA is dissected out from its mesenterial surroundings. At this point the SMA with the CT behind can be exposed if the assistant lifts the bowel mesentery cranially. The SMA together with the CT can be divided using a stapler (Figure 2). Care must be taken to stay $1 \mathrm{~cm}$ on top of the aorta above the origins of both vessels. Next the nasogastric tube is removed and both the hepatoduodenal ligament (if it hasn't been divided) and the oesophagus just below the diaphragm are divided so the entire stomach, duodenum, pancreas, spleen, with both small and large bowel can be mobilized and displaced out-

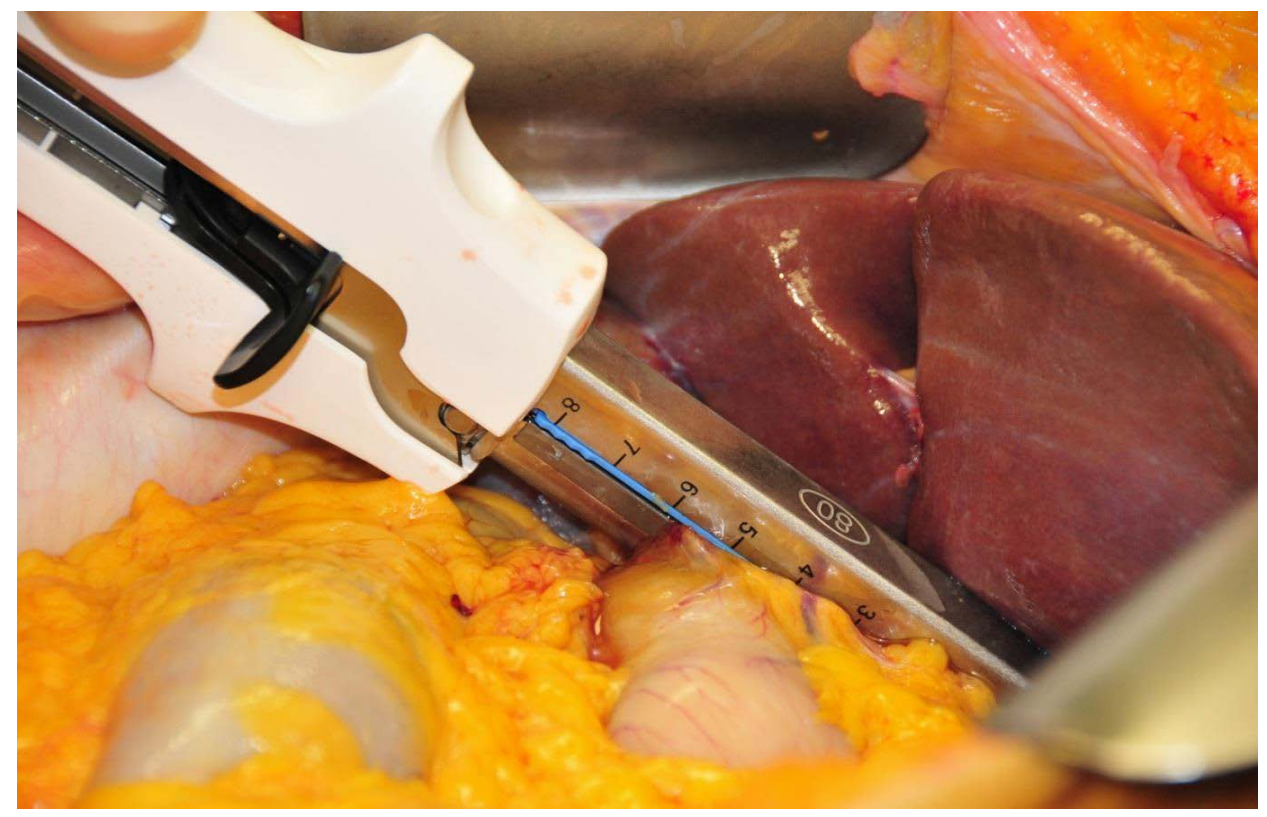

Figure 1. In difficult cases, the access to the supra-truncal aorta can be obtained by quick division of hepatoduodenal ligament using a vascular stapler with subsequent retracting of the liver cranially and to the right. 


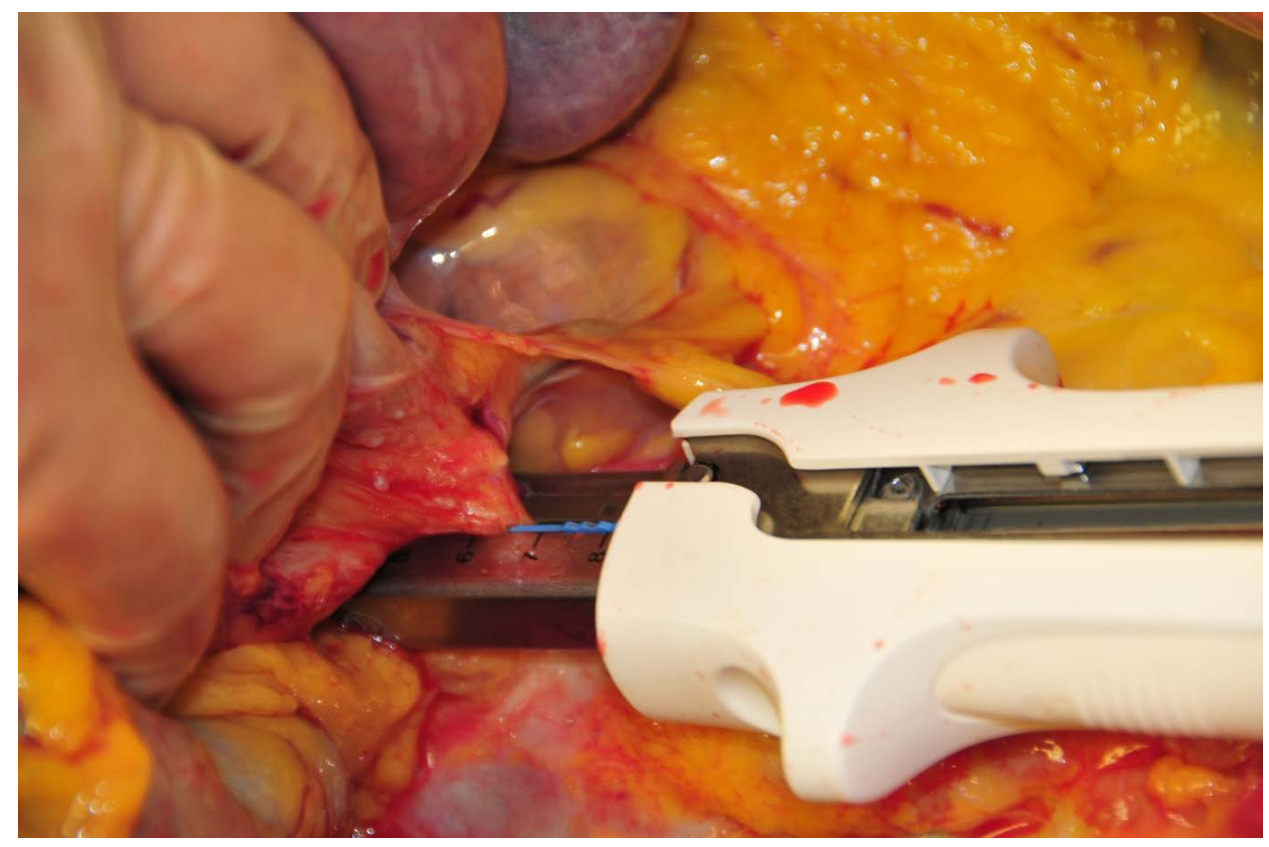

Figure 2. The Superior Mesenteric Artery (SMA) and Coeliac Trunk (CT) are divided with vascular stapler placed cranially and along the aorta at around $1 \mathrm{~cm}$ above the origin of these vessels.

side the abdominal cavity on the donor's upper legs (Figure 3 ).

The abdominal cavity is now filled with cold saline or Ringer's solution with sterile ice and the perfusion continued. Sterile ice and cold solution are replaced regularly (Figure 3). All of the above manoeuvres are meant to obtain a clear operative field with direct and easy access to both kidneys. The quality of perfusion is checked by the appearance of the kidneys (removing redundant fat if it is needed). The colour of the perfusate effluent coming out of the IVC is also checked and if found too red, extra amount of perfusion can be added. The kidneys are now procured according to the preference of the surgeon using separate or en-block technique as previously described [1]. It should be noted that if a thoracotomy is performed, the thoracic aorta is preferential clamped within the left pleural cavity and also venting can occur through the suprahepatic IVC. This could prevent less backflow from the liver into the IVC. It goes without saying that good understanding with thoracic procurement teams is important to achieve agreement on where to clamp and vent for a successful procedure.

\section{Discussion}

The Pittsburg rapid technique was the first standardized technique for procurement described by Thomas Starzl in 1987 [2] [3]. Today this technique is still being used by many procuring surgeons in the world with some modifications [1]. Since a standardized kidney only procurement has not been described, many surgeons use the standard multi-organ procurement technique to explant the kidneys but without removing the liver and pancreas. Other surgical options include just mobilizing the colon and then removing the kidneys like in live kidney donations. Unlike live donation the donor 


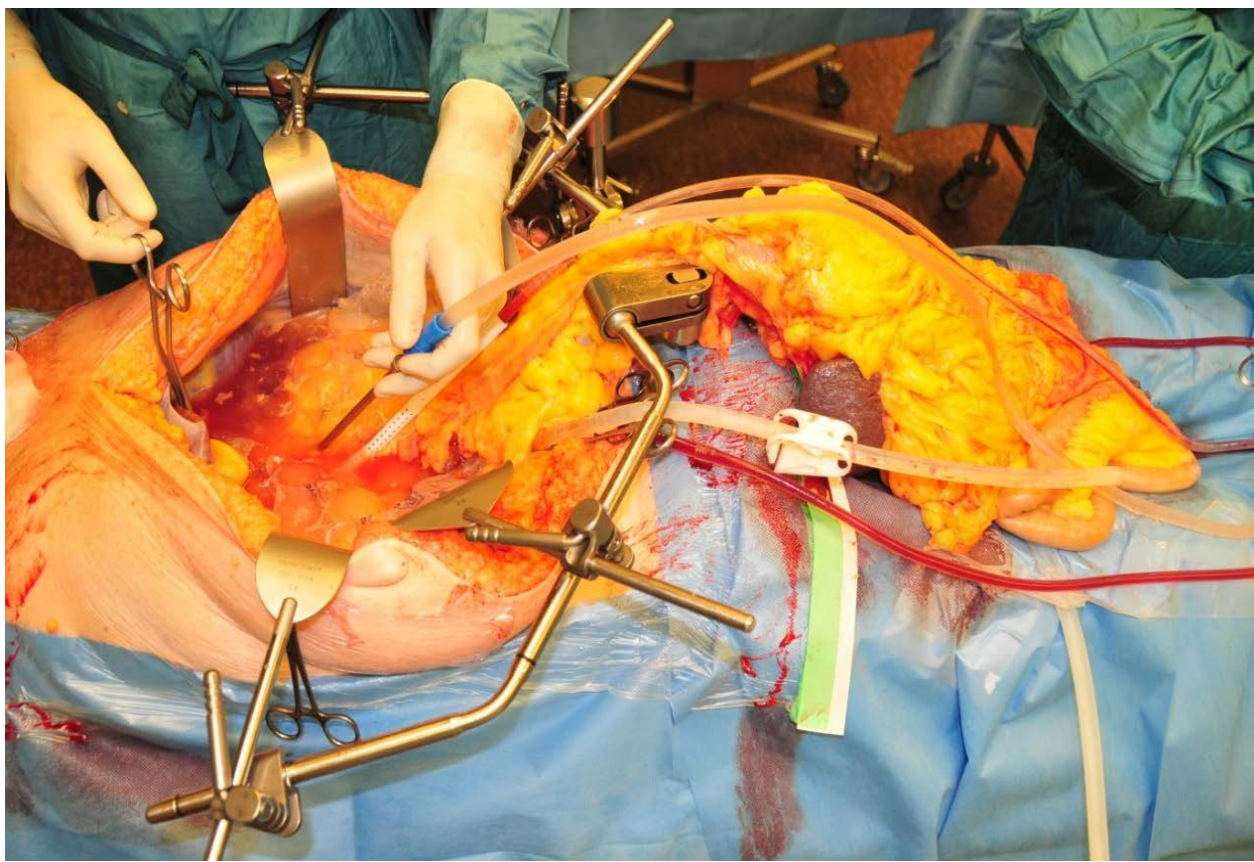

Figure 3. The entire stomach, duodenum, whole pancreas with spleen, with both small and large bowel and displaced outside the abdominal cavity on the donor's upper legs after full mobilization.

surgeon has limited knowledge of the kidney vascular and urological anatomy. In DCD with even more time pressure this could even translate in more injuries to the kidneys.

Without removing the pancreas, exposure and access to the kidney is less optimal. Standardisation and eviscerating bowels with pancreas, like our technique, could potentially improve exposure which in turn could lead to less iatrogenic injuries because of better access. Iatrogenic injuries to the kidneys may contribute to morbidity and impair renal function in the transplant recipient which translates into increased hospital stay and costs in a recent report [4]. Other reports have suggested otherwise with similar long-term graft survival [5] [6]. Surgical injuries were more frequently observed during single-organ procurements than during multi-organ procurements: $8.2 \%$ vs $3.7 \%$, respectively $(\mathrm{p}<0.05)$ [7]. Similarly, injuries were more frequent seen during donation after circulatory death (DCD) then donation after brain death (DBD) procurement: $(11.4 \%$ vs. $6.8 \%, \mathrm{p}<0.001)$ respectively [8]. Surgical damage was also seen with a less experienced surgeon ( $<30$ organ vs $>30$ procurements: $12 \%$ vs $3 \%$ respectively, $\mathrm{p}<0.01$ ) [7]. A standardized surgical technique after training and supervision of an experienced surgeon is therefore mandatory to increase the quality of organ procurement which in turn decreases the number of irreversibly damaged organs. This is the case in the Netherlands where a mandatory training course with certification is now required before surgeons are allowed to procure organs [9].

By stapling the SMA and CT, the perfusion of the whole gastro-intestinal tract is excluded. Hence more rapid perfusion with higher perfusion pressure will be going to the kidneys leading to potential better preservation of these organs. 


\section{Conclusion}

Our technique provides an easy, rapid and safe way to procure only kidneys in organ donation. Standardisation of kidney only procurements could lessen iatrogenic injuries to kidneys and may lead to less use of preservation fluid.

\section{References}

[1] Baranski, A. (2009) Surgical Technique of the Abdominal Organ Procurement. Springer, Leiden. http://dx.doi.org/10.1007/978-1-84800-251-7

[2] Starzl, T.E., Miller, C., Broznick, B. and Makowka, L. (1987) An Improved Technique for Multiple Organ Harvesting. Surgery, Gynecology \& Obstetrics, 165, 343.

[3] Starzl, T.E., Hakala, T.R., Shaw Jr., B.W., Hardesty, R.L., Rosenthal, T.J., Griffith, B.P., et al. (1984) A Flexible Procedure for Multiple Cadaveric Organ Procurement. Surgery, Gynecology \& Obstetrics, 158, 223.

[4] Wigmore, S.J., Seeney, F.M., Pleass, H.C., Praseedom, R.K. and Forsythe, J.L. (1999) Kidney Damage during Organ Retrieval: Data from UK National Transplant Database. Kidney Advisory Group. Lancet (London, England), 354, 1143. http://dx.doi.org/10.1016/S0140-6736(98)09409-4

[5] Castelo, D., Campos, L., Moreira, P., Furriel, F., Parada, B., Nunes, P., et al. (2013) Does Multiorgan versus Kidney-Only Cadaveric Organ Procurement Affect Graft Outcomes? Transplantation Proceedings, 45, 1248. http://dx.doi.org/10.1016/j.transproceed.2013.02.026

[6] Goldsmith, P.J., Ridgway, D.M., Pine, J.K., Speak, G., Newstead, C., Lewington, A.J., et al. (2010) Outcomes Following Renal Transplantation after Multiorgan Retrieval versus Kidney-Only Retrieval in Donation after Cardiac Death Donors. Transplantation Proceedings, 42, 3963. http://dx.doi.org/10.1016/j.transproceed.2010.09.145

[7] Eschwege, P., Droupy, S., Blanchet, P., Hammoudi, Y., Laassou, K., Hadj, A.E., et al. (2002) Surgical Injuries Occurring During Kidney Procurement Performed by a Renal Transplantation Team. Transplantation Proceedings, 34, 844. http://dx.doi.org/10.1016/S0041-1345(01)02931-1

[8] Ausania, F., White, S.A., Pocock, P. and Manas, D.M. (2012) Kidney Damage during Organ Recovery in Donation after Circulatory Death Donors: Data from UK National Transplant Database. American Journal of Transplantation: Official Journal of the American Society of Transplantation and the American Society of Transplant Surgeons, 12, 932.

[9] Nederlandse Transplantatie Stichting. Uitnamechirurgie. 2015.

\section{Abbreviation}

DCD: Donation after circulatory death;

DBD: Donation after brain death;

IVC: Inferior vena cava;

SMA: Superior Mesenteric Artery. 
Submit or recommend next manuscript to SCIRP and we will provide best service for you:

Accepting pre-submission inquiries through Email, Facebook, LinkedIn, Twitter, etc. A wide selection of journals (inclusive of 9 subjects, more than 200 journals)

Providing 24-hour high-quality service

User-friendly online submission system

Fair and swift peer-review system

Efficient typesetting and proofreading procedure

Display of the result of downloads and visits, as well as the number of cited articles

Maximum dissemination of your research work

Submit your manuscript at: http://papersubmission.scirp.org/

Or contact ojots@scirp.org 